\title{
Electrical Non-Linearity of SiC Aggregate
}

\author{
By \\ Takeshi MASUYAMA \\ (Wireless Research Laboratory, Matsushita Electric
Industrial Co., Ltd. Kadoma, Osaka
}

\section{Introduction}

It is well known that $\mathrm{SiC}$ is usually coated with an $\mathrm{SiO}_{2}$ layer at the surface and $\mathrm{SiO}_{2}$ layer serves as a protective coating for further oxidation. There have been many reports about the oxidation of $\mathrm{SiC}^{1), 2), 3}$. Suzuki ${ }^{4}$ has reported the relations among physical properties of $\mathrm{SiC}$, binding materials and the oxidation of $\mathrm{SiC}$.

However, there has been little attention to the effect of $\mathrm{SiO}_{2}$ layer on the semiconductive properties of $\mathrm{SiC}$. The $\mathrm{SiO}_{2}$ layer formed at the surface of $\mathrm{SiC}$ particles has very important role especially in the $\mathrm{SiC}$ non-linear resistor because the non-linear property of this resistor is attributed to contacts among individual $\mathrm{SiC}$ particles.

The $I-V$ characteristic of SiC particle aggregate has been aproximately expressed by the following equation ${ }^{5}$ :

$$
I=\left(\frac{V}{C}\right)^{\alpha}
$$

where $I$ is a current flowing through the aggregate and $V$ is a voltage applied to the aggregate. According to Schwertz et $\mathrm{al}^{5)}$., $C$ and $\alpha$ are constants independent of $I$ and $V$ and are dependent on the dimension and shape of the aggregate or on the preparation conditions. They conclude that the $C$ relates to the pressure, $P$, applied to the aggregate by the following equation.

$$
C \propto P^{-i / m}
$$

where $m$ is a constant ranging 3 to 3.5 :

The $C$-value is named a non-linear resistance and corresponds to a resistance of usual ohmic resistor having $\alpha=1$.

These $I-V$ characteristics of $\mathrm{SiC}$ particles have not been discussed in view of the $\mathrm{SiO}_{2}$ layer formed at the surface of $\mathrm{SiC}$ particles. The present paper is to study the voltage non-linear properties of $\mathrm{SiC}$ particles while considering the effects of $\mathrm{SiO}_{2}$ layer on the surfaces of $\mathrm{SiC}$ particles.

\section{Experimental}

\subsection{Measurement on SiC Aggregate}

The SiC particles having an average size of 60 to $180 \mu$ were placed in a ceramic cylinder of 13 $\mathrm{mm}$ in diameter and were pressed by an upper
Table 1 Properties of $\mathrm{SiC}$ used in varistor.

\begin{tabular}{cccc}
\hline Impurity Content $(\%)$ & Resistivity $(\mathrm{k} \Omega)$ & Color \\
$\mathrm{Al}$ & 0.18 & 200 & Black \\
\hline 0.32 & & & \\
\hline
\end{tabular}

and lower punches acting as electrodes.

The $I-V$ characteristics were measured by applying dc current through the both punches while the pressure of the upper punch was changed from $0.1 \mathrm{~kg} / \mathrm{cm}^{2}$ to $800 \mathrm{~kg} / \mathrm{cm}^{2}$. Table 1 shows the impurity content and electrical resistance of $\mathrm{SiC}$ particles used. The resistance of the $\mathrm{SiC}$ particles was conveniently represented by the resistance obtained when dc current of $1 \mathrm{~mA}$ was supplied to a compact body pressed at 400 $\mathrm{kg} / \mathrm{cm}^{2}$. The compact body was composed of $\mathrm{SiC}$ particles in an average size of $113 \mu$ and had a dimension of $4 \mathrm{~mm}$ in diameter.

\subsection{Calculation of $\alpha$-value and Definition} of Non-Linear Resistance $C$

The $\alpha$-value is calculated by the following equation (3) lead from equation (1):

$$
\alpha=\frac{d(\log I)}{d(\log V)}=\frac{d I}{I} / \frac{d V}{V} \fallingdotseq \frac{\log I_{1}-\log I_{2}}{\log V_{1}-\log V_{2}}
$$

where $I_{1}$ and $I_{2}$ are current flowing through the varistor at $V_{1}$ and $V_{2}$, respectively.

The obtained value is defined as an $\alpha$-value at a voltage of $\left(V_{1}+V_{2}\right) / 2$. The non-linear resistance $C$ is conveniently defined as a resistance when $1 \mathrm{~mA}$ of current flows.

\section{Results and Discussion}

\section{$3.1 I-V$ Characteristics}

Fig. 1 shows typical $I-V$ curves of $\mathrm{SiC}$ aggregate. As easily understood by equation (3); the reciprocal of slope of the $I-V$ curve indicates $\alpha$-value; the larger slope results in the smaller $\alpha$-value. The slope becomes steeper with a decrease in the applied voltage or in the current as well as with an increase in the pressure. It is concluded that the $\alpha$ is not constant but dependent upon applied voltage, current and pressure.

Fig. 2 shows the relation between the compacting pressure and the $\alpha$-value at a given voltage. Below $5 \mathrm{~kg} / \mathrm{cm}^{2}$ the $\alpha$-value increases with incre- 


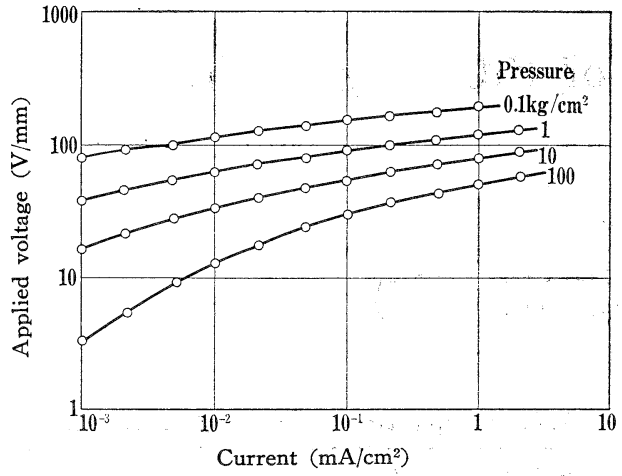

Fig. $1 I-V$ properties of $\mathrm{SiC}$ aggragate as a parameter of applied pressure.

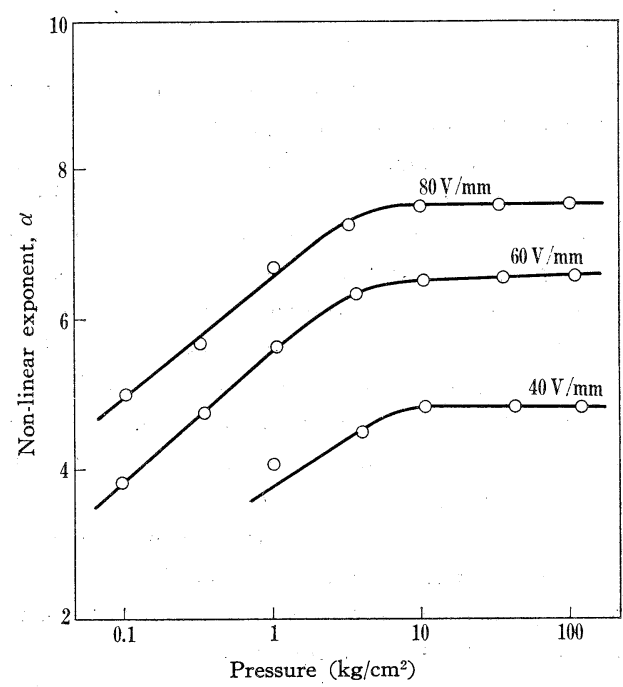

Fig. 2 Relations between compacting pressure and $\alpha$ at constant voltages.

asing compacting pressure. However, the aggregate compacted at a pressure more than $5 \mathrm{~kg} / \mathrm{cm}^{2}$ shows a constant $\alpha$-value.

Therefore, the $V-\alpha$ curves are represented by an identical line as shown in Fig. 3 even when the aggregate is pressed at various pressures

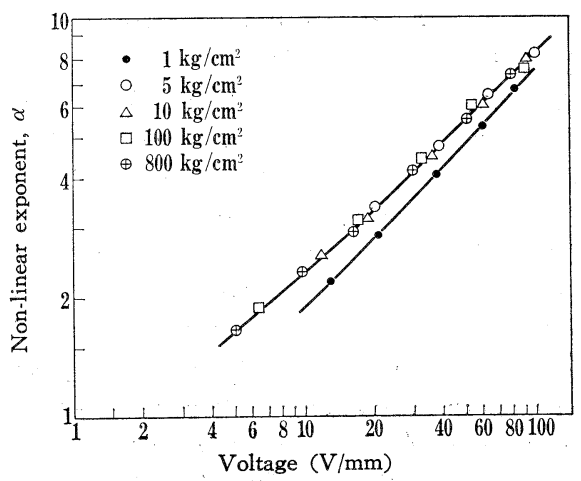

Fig. $3 \quad V-\alpha$ properties of $\mathrm{SiC}$ aggregate at various compacting pressures. above $5 \mathrm{~kg} / \mathrm{cm}^{2} . \quad V-\alpha$ relation of Fig. 3 is approximately linear in logarithmic scale and ${ }_{1}^{\text {Fen }}$ be expressed by the following experimental equation:

$$
\alpha=b V^{a} \text {. }
$$

where $a$ and $b$ are constants independent voltage. Fig. 3 indicates that at a pressure above $5 \mathrm{~kg} / \mathrm{cm}^{2} \quad a$ and $b$ are also independent of the compacting pressure. From equations (3) and (4),

$$
\frac{d(\log I)}{d(\log V)}=b V^{a}=b e^{a \log V}
$$

Accordingly,

$$
I=k e^{\frac{b}{a} V^{a}} \equiv k e^{b_{0} V^{a}}
$$

where $k$ is constant.

Fig. 3 exhibits that the $\mathrm{SiC}$ has about $1 / 2$ of $a$-value for a pressure above $5 \mathrm{~kg} / \mathrm{cm}^{2}$. According to the measurements with various $\mathrm{SiC}$ particles, the $a$-value above $5 \mathrm{~kg} / \mathrm{cm}^{2}$ was independent of the kinds of $\mathrm{SiC}$ particles and was also about $1 / 2$. The $b$-value depended on the kinds of $\mathrm{SiC}$ particles and decreased with an increace in the resistivity of $\mathrm{SiC}$ particles.

\subsection{Effect of Oxidation of SiC Particles}

The voltage non-linear properties of the $\mathrm{SiC}$ aggregate are known to be attributed to contacts among individual $\mathrm{SiC}$ particles ${ }^{6}$. The surface state of $\mathrm{SiC}$ particle is greatly responsible for the non-linear property of aggregate. Therefore, it is interesting to examine the effect of $\mathrm{SiO}_{2}$ film formed on $\mathrm{SiC}$ particle on the $\alpha$-value.

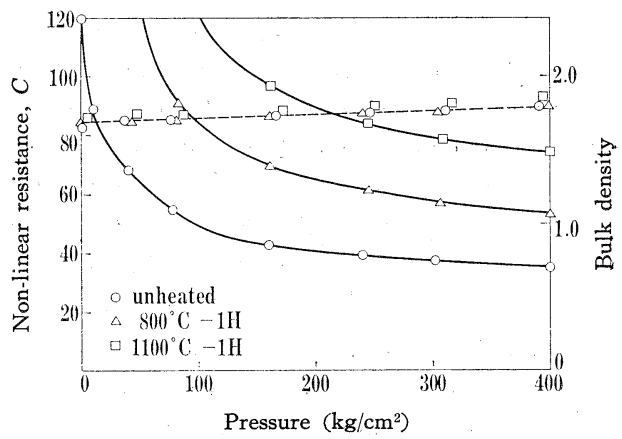

Solid lines : $C$

Dotted line : bulk density

Fig. 4 Relation of $C$ and bulk density of $\mathrm{SiC}$ aggregate as a function of applied pressure.

The $\mathrm{SiC}$ particles as crushed were heated at a temperature of $800^{\circ}$ to $1300^{\circ} \mathrm{C}$ for 1 hour in order to from a thin $\mathrm{SiO}_{2}$ film on the surface. Fig. 4 shows a relation between applied pressure and non-linear resistance $C$, or bulk density of $\mathrm{SiC}$ particles oxidized 'at various temperature. The $\mathrm{SiC}$ particles show a logarithmic decrease in the non-linear resistance $C$ and a linear increase in the bulk density with increasing pressure. The non-linear resistance $C$ decreases initially steeply 


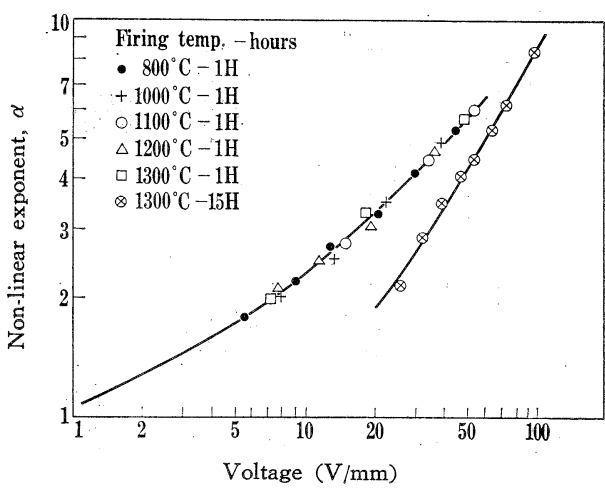

Fig. $5 \quad V-\alpha$ properties of $\mathrm{SiC}$ aggregate pressed at $150 \mathrm{~kg} / \mathrm{cm}^{2}$. SiC particles are fired in air at various temperatures.

with a compacting pressure below $150 \mathrm{~kg} / \mathrm{cm}^{2}$ and gradually above $150 \mathrm{~kg} / \mathrm{cm}^{2}$. The higher oxidation temperature results in the higher non-linear resistance $C$; the bulk density does not vary with the oxidation temperature.

As shown is Fig. 5, the $V-\alpha$ curve did not vary with the heating temperature of $800^{\circ}$ to $1300^{\circ} \mathrm{C}$ for 1 hour and was similar to that of unheated $\mathrm{SiC}$ particles when the $\mathrm{SiC}$ particles were pressed at $150 \mathrm{~kg} / \mathrm{cm}^{2}$. The $\mathrm{SiC}$ particles heated in air at $1300^{\circ} \mathrm{C}$ for 15 hours, however, exihibited a $V-\alpha$ curve different from that of $\mathrm{SiC}$ particles heated in air at $1300^{\circ} \mathrm{C}$ for 1 hour.

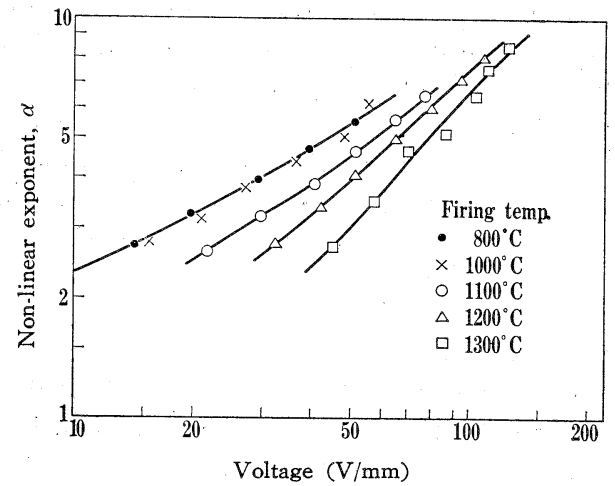

Fig. $6 \quad V-\alpha$ properties of $\mathrm{SiC}$ aggregate pressed at $5 \mathrm{~kg} / \mathrm{cm}^{2}$. SiC particles are fired in air at various temperatures for 1 hour.

The $V-\alpha$ curve at $5 \mathrm{~kg} / \mathrm{cm}^{2}$, however, varied with the heating temperature of ' $\mathrm{SiC}$ particles. Fig. 6 shows that the $V-\alpha$ curve shifts toward the higher voltage as the heating temperature of $\mathrm{SiC}$ particles rises. The $V-\alpha$ curve for $\mathrm{SiC}$ particles heated at $800^{\circ} \mathrm{C}$ is exactly similar to that for $\mathrm{SiC}$ particles heated at $1000^{\circ} \mathrm{C}$. From the comparison of Fig. 5 with Fig. 6, it can be seen that there is no difference in $V-\alpha$ curve between the $\mathrm{SiC}$ particles pressed at $150 \mathrm{~kg} / \mathrm{cm}^{2}$ and $5 \mathrm{~kg} / \mathrm{cm}^{2}$ when the $\mathrm{SiC}$ particles are heated at $800^{\circ}$ to $1000^{\circ} \mathrm{C}$.
The $V-\alpha$ curves of Fig. 5 and 6 will be explained by considering the thickness of thin film of $\mathrm{SiO}_{2}$ formed by oxidation. The thickness of thin film can be expressed by the following equation ${ }^{2}$ :

$$
\left.\begin{array}{l}
\delta_{0}{ }^{2}=K t \\
\log K=13.7-17500 / T
\end{array}\right\}
$$

where $\delta_{0}$ is a thickness of $\mathrm{SiO}_{2}$ film $(\mathrm{m} \mu)$; $t$, a heating time (minute); and $T$ is a temperature in absolute $\left({ }^{\circ} \mathrm{K}\right)$. The thickness of $\mathrm{SiO}_{2}$ film is calculated to be $20 \mathrm{~m} \mu$ and $70 \mathrm{~m} \mu$ when the $\mathrm{SiC}$ particles are heated in air at $1300^{\circ} \mathrm{C}$ for 1 hour and 15 hours, respectively.

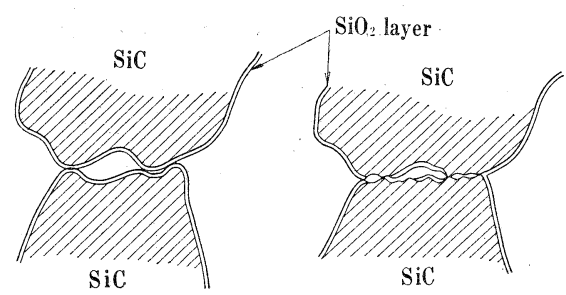

(a) Contact pressed below (b) Contact pressed above critical pressure. critical pressure.

Fig. 7 Model of $\mathrm{SiC}$ to $\mathrm{SiC}$ contact.

The SiC particles are brittle and show no plastic deformation like metal powders when pressed at high pressure. In view of similarity in $V-\alpha$ curve at $150 \mathrm{~kg} / \mathrm{cm}^{2}$ between $\mathrm{SiC}$ particles heated at $1300^{\circ} \mathrm{C}$ for 1 hour and unheated $\mathrm{SiC}$ particles, it will be concluded that the compacting pressure of $150 \mathrm{~kg} / \mathrm{cm}^{2}$ makes it possible to break partially the $\mathrm{SiO}_{2}$ film of $20 \mathrm{~m} \mu$ in thickness and to bring the $\mathrm{SiC}$ particles into direct contacts as shown in Fig. 7. The difference in $V-\alpha$ curve for $\mathrm{SiC}$ particles heated at $1300^{\circ} \mathrm{C}$ for 15 hours and that for $\mathrm{SiC}$ particles heated at $1300^{\circ} \mathrm{C}$ for 1 hour indicates that the $\mathrm{SiO}_{2}$ film of $77 \mathrm{~m} \mu$ in thickness can not be broken by the pressure of $150 \mathrm{~kg} / \mathrm{cm}^{2}$ and prevents direct contacts between the $\mathrm{SiC}$ particles. The change in the bulk density and the $C$ with increasing pressure is also attributed to an increase in the contact area among the $\mathrm{SiC}$ particles, which is due to a promotion of pulverization at the edge contacts as shown in Fig. 7. Such pulverization was proved by microscopic observation of aggregate pressed at a high pressure.

It is interesting to know a relation between the thickness of $\mathrm{SiO}_{2}$ film and a critical pressure by which the $\mathrm{SiO}_{2}$ film starts to be broken. The $\mathrm{SiC}$ particles were heated in air at various temperature for various heating time periods so that their surfaces are coated by $\mathrm{SiO}_{2}$ films having various thicknesses. The thickness can be calculated in accordance with the equation (6). The $\alpha$ of $\mathrm{SiC}$ particles coated with $\mathrm{SiO}_{2}$ films in various thicknesses was plotted against the pressure in 


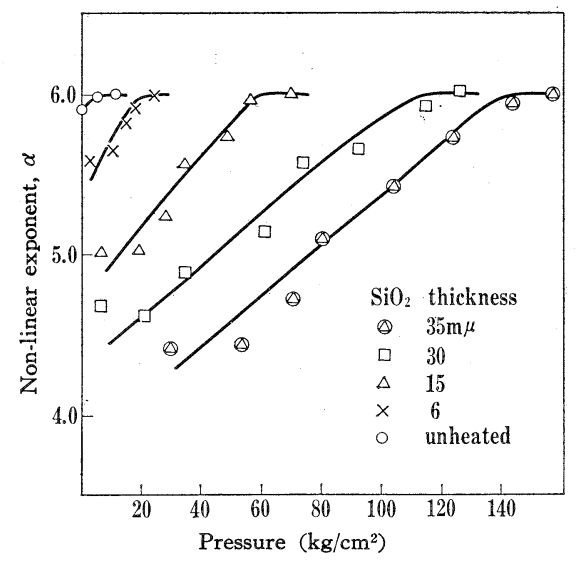

Fig. 8 Relations between applied pressures and $\alpha$ for $\mathrm{SiC}$ particles having $\mathrm{SiO}_{2}$ layers of various thicknesses.

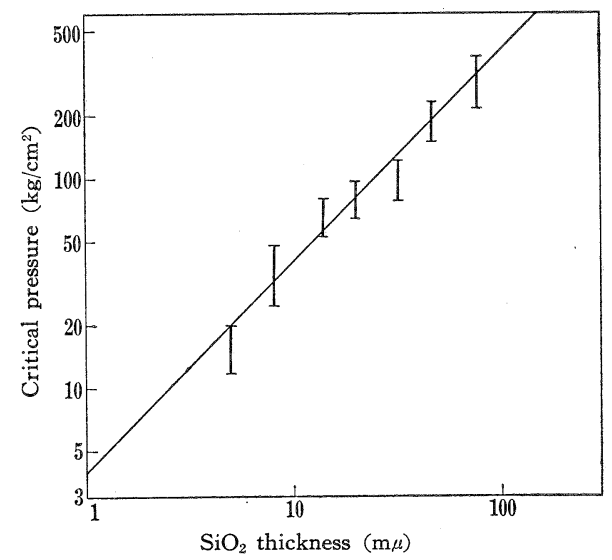

Fig. 9 Relations between $\mathrm{SiO}_{2}$ thickness and critical pressure.

Fig. 8 ; the $\alpha$ was measured at $60 \mathrm{~V} / \mathrm{mm}$. Fig. 8 indicates that the $\alpha$ increases with an increase in the pressure and is constant above a critical pressure. The constant $\alpha$-value above the critical pressure may be resulted from the direct contacts of $\mathrm{SiC}$ particles due to the damage of the $\mathrm{SiO}_{2}$ film. Note that the unheated $\mathrm{SiC}$ particles has a critical pressure of about $5 \mathrm{~kg} / \mathrm{cm}^{2}$.

The critical pressure increases linearly with the thickness of $\mathrm{SiO}_{2}$ film as shown in Fig. 9. In view of a critical pressure of $5 \mathrm{~kg} / \mathrm{cm}^{2}$ for unheated $\mathrm{SiC}$ particles, it will be concluded that the unheated $\mathrm{SiC}$ particles are coated with $\mathrm{SiO}_{2}$ film in about $1 \mathrm{~m} \mu$ thickness. It is noteworthy that the value of $1 \mathrm{~m} \mu$ in thickness corresponds to that of previous reports $\left.{ }^{7}, 8\right)$.

\subsection{Pressure Dependence of $\alpha$ and $C$}

The relation between the $\alpha$-value and the applied pressure below critical pressure can be explained with a simple aggregate model in which $\mathrm{SiC}$ particles coated with ohmic $\mathrm{SiO}_{2}$ films are in

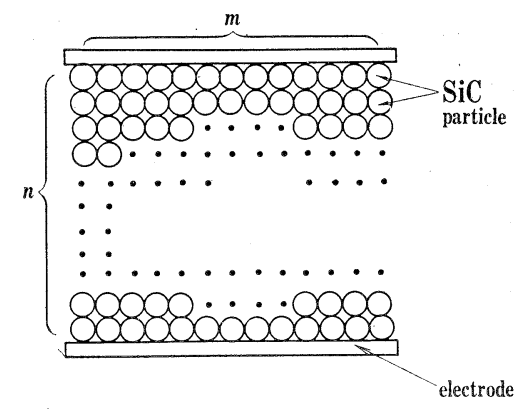

Fig. 10 Simplified model of $\mathrm{SiC}$ aggregate.

contact to each other.

Assume a simple aggregate composed of $m$ trains, each of which comprises $n$ SiC spheres aligned in a longitudinal line as shown in Fig. 10. An electric voltage $V_{1}$ applied across the top layer and the bottom layer causes a current $I_{1}$ to flow through the aggregate in a longitudinal direction. Since the $\mathrm{SiC}$ particles themselves have a resistance extremely lower than that of the contact between $\mathrm{SiC}$ particles, the $V_{1}$ and $I_{1}$ can be expressed by the following equation:

$$
\left.\begin{array}{l}
V_{1}=n v_{1} \\
I_{1}=m i_{1}
\end{array}\right\}
$$

where $v_{1}$ is a voltage applied to each of contacts between $\mathrm{SiC}$ particles and $i_{1}$ is a current flowing through each of the trains. When the $\mathrm{SiC}$ particles have no $\mathrm{SiO}_{2}$ layer on the surfaces, the $V-I$ characteristic of each $m$ trains containing $n \mathrm{SiC}$ particles aligned in a longitudinal direction is assumed by the following equation:

$$
i_{1}=K_{1} v_{1}{ }^{\alpha_{1}}
$$

where $\alpha_{1}$ is defined as the non-linear exponent of $\mathrm{SiC}$ particles having no $\mathrm{SiO}_{2}$ Iayer. By combining the equation (7) and (8), one obtains;

$$
I_{1}=m K_{1}\left(\frac{V_{1}}{n}\right)^{\alpha_{1}}
$$

When the SiC particles of the aggregate are coated with the $\mathrm{SiO}_{2}$ films formed by oxidation, the voltage $V$ applied to the aggregate is divided into two parts: One is the voltage, $V_{1}$ applied to $\mathrm{SiC}$ particles and the other is the voltage, $V_{2}$ applied to $\mathrm{SiO}_{2}$ films. Therefore, one can obtain,

$$
V=V_{1}+V_{2}
$$

Assume that the $\mathrm{SiO}_{2}$ films have a constant resistance $R_{0}$, and one obtain:

$$
\begin{aligned}
V_{2} / V_{1} & =\frac{\text { Resistance of } \mathrm{SiO}_{2} \text { films }}{\text { Resistance of } \mathrm{SiC} \text { particles }} \\
& =I_{1} R_{0} / V_{1} \\
& =\frac{R_{0} m K_{1}}{n^{\alpha_{1}}} V_{1}^{\alpha_{1}-1}
\end{aligned}
$$

Hence,

$$
V_{2}=\left(R_{0} m K_{1} / n^{\alpha_{1}}\right) V_{1}^{\alpha_{1}} \equiv k V_{1}^{\alpha_{1}}
$$

One can calculate the $\alpha$-value of the aggregate of $\mathrm{SiC}$ particles coated with $\mathrm{SiO}_{2}$ films as follows: 


$$
\begin{aligned}
& \alpha=\frac{d I_{1}}{I_{1}} / \frac{d V}{V} \\
& =\frac{d I_{1}}{I_{1}} / \frac{\left(1+\alpha_{1} k V_{1}^{\alpha_{1}-1}\right) d V_{1}}{\left(V_{1}+k V_{1}^{{ }_{1}}\right)} \\
& =\frac{d I_{1}}{I_{1}} / \frac{\left(V_{1}+\alpha_{1} V_{2}\right) d V_{1}}{\left(V_{1}+V_{2}\right) V_{1}} \\
& =\left(\frac{V_{1}+V_{2}}{V_{1}+\alpha_{1} V_{2}}\right) \alpha_{1} \\
& =\left(1+\frac{V_{2}}{V_{1}}\right) \alpha_{1} /\left(1+\frac{\alpha_{1} V_{2}}{V_{1}}\right) \\
& =\alpha_{1}\left\{1+\left(1-\alpha_{1}\right) \frac{V_{2}}{V_{1}}-\alpha_{1}\left(1-\alpha_{1}\right)\left(\frac{V_{2}}{V_{1}}\right)^{2}+\right. \\
& \alpha_{1}^{2}\left(1-\alpha_{1}\right)\left(\frac{V_{2}}{V_{1}}\right)^{3}+\cdots \cdots \cdots \cdots \\
& \doteqdot \alpha_{1}\left\{1-\left(\alpha_{1}-1\right) \frac{V_{2}}{V_{1}}\right\}
\end{aligned}
$$

The ratio $V_{2} / V_{1}$ decreases as the thickness of $\mathrm{SiO}_{2}$ film is lowered by the pulverization due to the increasing pressure. When the two particles are in direct contact to each other at the critical pressure, the ratio $V_{2} / V_{1}$ becomes 0 and $\alpha$ is in accord with $\alpha_{1}$. From the equation (9), it will be clear that the $\alpha$-value of aggregate increases with an increase in the pressure below the critical pressure and reaches $\alpha_{1}$ when the two $\mathrm{SiC}$ particles are in direct contact to each other above the critical pressure.

Fig. 4 indicates that the $C$-value still decreases with an increase in the pressure above critical value. The relation between $C$ and pressure can be explained as follows:

The direct contact between SiC particles above critical pressure is responsible for the constant $\alpha$ at a given voltage as stated above. An area of direct contact between $\mathrm{SiC}$ particles, however, increases as the applied pressure increases. Since the current passing through the $\mathrm{SiC}$ particles is found to be proportional to the direct contact areas of $\mathrm{SiC}$ particles, the current at a given voltage increases with an increase in the applied pressure. This means that the voltage at a given current decreases inversely with an increase in the applied pressure. The voltage at a given current is equivalent to the $C$ in view of the definition shown in 2-2. Therefore, the $C$ decreases monotonously with an increase in the applied pressure though the voltage at a given $\alpha$ is independent of the pressure above critical value. It should be noted that the direct contact of $\mathrm{SiC}$ particles is resulted in a constant $\alpha$ but not in the constant $C$-value.

The area of direct contact between $\mathrm{SiC}$ particles decreases with an increase in a thickness of $\mathrm{SiO}_{2}$ layer formed on $\mathrm{SiC}$ particle at a given pressure. Therefore, as seen in Fig. 4, the $\mathrm{SiC}$ particles heated at a higher temperature show a higher $C$-value at a given pressure because they have a thicker $\mathrm{SiO}_{2}$ layer.

\section{Conclusion}

The $V-I$ property of $\mathrm{SiC}$ aggregate is expressed by the following equation:

$$
I=\left(\frac{V}{C}\right)^{\alpha}
$$

where $\alpha$ is a nonlinear exponent and $C$ is a constant corresponding with the resistance in an ohmic resistor. The study on the non-linearity of $\mathrm{SiC}$ aggregate has led the following conclusions :

1) The $\mathrm{SiC}$ particles as crushed is provided with the $\alpha$ which increase with an increase in the applied pressure below a critical pressure of 5 $\mathrm{kg} / \mathrm{cm}^{2}$. Above the critical pressure, the $\alpha$ at a given voltage keeps constant regardless of a change in the pressure.

2) The relation between the $\alpha$ and the applied voltage is expressd as follows:

$$
\alpha=b V^{a}
$$

where $a$ and $b$ are constants. Above the critical pressure, the $a$-value is independent of the applied pressure and kinds of $\mathrm{SiC}$ particles and is about $1 / 2$. The $b$-value decreases with an increase in the resistivity of $\mathrm{SiC}$. In view of this relation of the $\alpha$ to the applied voltage, the $V-I$ property of $\mathrm{SiC}$ particles can be expressed by the following equation:

$$
I=k e^{b_{0} V^{a}}, b_{0} \equiv b / a
$$

where $k$ is a constant.

3) The critical pressure becomes higher as the $\mathrm{SiC}$ particles are coated with a thicker $\mathrm{SiO}_{2}$ film formed by oxidation. The formation of $\mathrm{SiO}_{2}$ layer on $\mathrm{SiC}$ particles causes the lower $\alpha$ below the critical pressure and the higher $C$-value regardless of the applied pressure.

4) The relation between $\alpha$ and pressure below the critical pressure has been discussed in view of the thickness of $\mathrm{SiO}_{2}$ layer formed on $\mathrm{SiC}$ particles.

\section{Acknowledgement}

The auther wishes to express his appreciation to Prof. S. Kachi of Kyoto University for his useful comments. The author also thanks to Dr. S. Kisaka and Dr. Y. Iida for their continual encouragement and helpful discussions. Thanks are due to Messrs. K. Hamamoto and I. Nakabayashi for their assistances in experiments.

\section{References}

1) A.C. Lea, J. Soc. Glasss Technol. 12, 27-50 (1949).

2) G. Ervin, J. Am. Ceram. Soc. 41, 347-52 (1958).

3) T.H. Elmer, U.S. Atomic Energy Doc. NEPA1770 (1950).

4) S. Yamauchi, "Yogyo no Kenkyu II" Gihodo (1961). pp. 429-86.

5) F.A. Schwertz and J.J. Mazenko, J. Appl. Phys. 24, 1015-1024 (1953). 
6) E.W.J. Mitchell and R.W. Sillars, Proc. Phys. Soc. 62 B, 509-22 (1949).

7) A. Braun and G. Busch, Helv. Phys. Acta 15, 571-611 (1942).
8) H.G. Heine and P. Scherrer, Helv. Phys. Acta 13, 489 (1940).

\title{
$\mathrm{SiC}$ 粒子集合体の電気的非直線性
}

\author{
增 山 \\ （松下電器産業 (株) 無線研究所)
}

\author{
本論文は $\mathrm{SiC}$ 粒子の表面に形成されている $\mathrm{SiO}_{2}$ の \\ 影響を考慮に 入れた場合の $\mathrm{SiC}$ 粒子集合体の 電圧非直 \\ 線特性についてのべる. \\ 非直線性は $I=(V / C)^{\alpha}$ の式で表示される。粉砕され \\ たままの $\mathrm{SiC}$ 粒子の $\alpha$ は, $5 \mathrm{~kg} / \mathrm{cm}^{2}$ の臨界圧力以下の \\ 印加圧力で, 圧力の増加とともに大きくなる. 臨界圧力

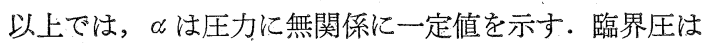 \\ $\mathrm{SiC}$ 粒子表面に形成される $\mathrm{SiO}_{2}$ の厚みが厚くなると大
}

きくなる. $\alpha$ と電圧の間には $\alpha=b V^{a}$ の関係がある.臨 界圧以上では $a$ は電圧, 圧力, $\mathrm{SiC}$ 粒子の種類に 無 関 係に一定である. 臨界圧以下における $\alpha$ の圧力依存性 は, $\mathrm{SiO}_{2}$ 層の厚みが 圧力とともに変ることによってお こる. $\mathrm{SiO}_{2}$ 層の厚みは印加圧力が増大寸るにつれて減 少する. $\mathrm{SiO}_{2}$ 層の $\alpha$ におよぼす影響について論じられ ている.

(3/10/1969 受付)

\section{The Properties and Structure of Glasses in the System $\mathbf{A s}_{2} \mathbf{S}_{3}-\mathbf{S b}_{2} \mathbf{S}_{3}$}

(The Properties and Structure of Sulfide Glasses Part IV)

By

\author{
Yoji KAWAMOTO and Shoji TSUCHIHASHI \\ (Department of Chemistry, Faculty of Science, Kobe University, Rokkodai, Kobe)
}

\section{Introduction}

The physical and chemical properties of glasses in the system As-S and the structure derived from the various properties were reported in the previous papers $^{1,2,3)}$. We have now intended the investigation of glasses in the system $\mathrm{Sb}-\mathrm{S}$ in which $\mathrm{Sb}$ is of the same group as As in the Periodic Table. However the vitreous material could not be obtained in the binary system Sb-S.

Therefore it was thought advisable to investigate the structure and properties of glasses in which $\mathrm{Sb}$ was added to the system As-S for the following reasons; in view of a fact that $\mathrm{Sb}$ is more metallic than As and the structure of $\mathrm{Sb}_{2} \mathrm{~S}_{3}$ (a double chain structure, m.p. $548^{\circ} \mathrm{C}$ ) is very different from that of $\mathrm{As}_{2} \mathrm{~S}_{3}$ (a layer structure,

A part of this paper was read at the Meeting of the Chemical Society of Japan in Okayama on October, 1967 and in Tokyo on April, 1969. m.p. $310^{\circ} \mathrm{C}$ ) (Fig. 1), it is very interest to investigate how the properties of these glasses change by the addition of $\mathrm{Sb}$ to As-S glasses or how the glass in this system is built up.

The tendency of glass formation in the system As- $\mathrm{S}-\mathrm{Sb}$ has been already reported by Kolomiets et al. ${ }^{4)}$, but its range is not determined in detail

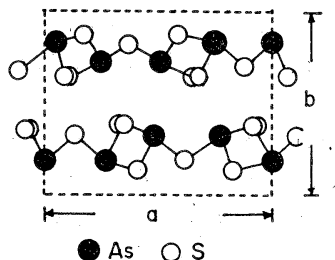

(1)

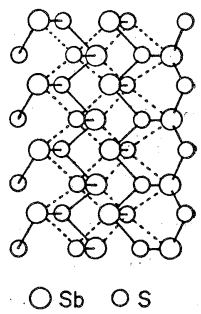

(2)
Fig. 1 The structure of $\mathrm{As}_{2} \mathrm{~S}_{3}$ "crystal (orpiment) (1) and $\mathrm{Sb}_{2} \mathrm{~S}_{3}$ crystal (stibnite) (2). 